\title{
Autonomic responses to exercise: Group III/IV muscle afferents and fatigue $\mathrm{i}^{\mathrm{s}}$
}

\author{
Markus Amann a,b,*, Simranjit K. Sidhu ${ }^{\text {a }}$, Joshua C. Weavil ${ }^{\text {b }}$, Tyler S. Mangum ${ }^{\text {b }}$, Massimo Venturelli ${ }^{\text {c }}$ \\ a Department of Medicine, University of Utah, Salt Lake City, UT, USA \\ ${ }^{\mathrm{b}}$ Department of Exercise E' Sport Science, University of Utah, Salt Lake City, UT, USA \\ c Department of Biomedical Sciences for Health, University of Milan, Italy
}

\section{A R T I C L E I N F O}

\section{Article history:}

Received 12 June 2014

Received in revised form 17 September 2014

Accepted 13 October 2014

\section{Keywords:}

Neural feedback

Central fatigue

Exercise pressor reflex

Circulation

Ventilation

\begin{abstract}
A B S T R A C T
Group III and IV muscle afferents originating in exercising limb muscle play a significant role in the development of fatigue during exercise in humans. Feedback from these sensory neurons to the central nervous system (CNS) reflexively increases ventilation and central (cardiac output) and peripheral (limb blood flow) hemodynamic responses during exercise and thereby assures adequate muscle blood flow and $\mathrm{O}_{2}$ delivery. This response depicts a key factor in minimizing the rate of development of peripheral fatigue and in optimizing aerobic exercise capacity. On the other hand, the central projection of group III/IV muscle afferents impairs performance and limits the exercising human via its diminishing effect on the output from spinal motoneurons which decreases voluntary muscle activation (i.e. facilitates central fatigue). Accumulating evidence from recent animal studies suggests the existence of two subtypes of group III/IV muscle afferents. While one subtype only responds to physiological and innocuous levels of endogenous intramuscular metabolites (lactate, ATP, protons) associated with 'normal', predominantly aerobic exercise, the other subtype only responds to higher and concurrently noxious levels of metabolites present in muscle during ischemic contractions or following, for example, hypertonic saline infusions. This review discusses the mechanisms through which group III/IV muscle afferent feedback mediates both central and peripheral fatigue in exercising humans. We also briefly summarize the accumulating evidence from recent animal and human studies documenting the existence of two subtypes of group III/IV muscle afferents and the relevance of this discovery to the interpretation of previous work and the design of future studies.
\end{abstract} (C) 2014 Elsevier B.V. All rights reserved.

\section{Introduction}

Both whole body (e.g. cycling) and single joint (e.g. isometric/ dynamic knee extension) exercise of sufficient duration and intensity reduce the force/power generating capacity of muscles involved in the task. This exercise-induced decrease is determined by a peripheral and a central [i.e. related to the central nervous system (CNS)] component (Allen et al., 2008; Gandevia, 2001). 'Peripheral fatigue' encompasses biochemical changes within the contracting muscle leading to an attenuated force/power response to neural excitation. 'Central fatigue', structurally including the brain and the spinal cord, refers to the decrease in force/power secondary to a reduction in descending motor drive and the efficacy of the afferent pathways which combined result in a decrease in the output from spinal motoneurons and thus voluntary muscle activation. Both components of fatigue have previously been linked to group III and IV muscle afferent feedback.

\footnotetext{
Funding for this work was received from the National Institutes of Health (HL-103786 and HL-116579) and the American Heart Association (AHA 14 17770016).

* Corresponding author at: VA Medical Center, 500 Foothill Drive, GRECC 182, Salt Lake City, UT 84148, USA. Tel.: + 1801582 1565x4358; fax: + 18015845658.

E-mail address: markus.amann@hsc.utah.edu (M. Amann).
}

In order to assure a sufficient link to the original work in the face of a restricted number of references, we would be citing various other review articles.

\subsection{Group III/IV muscle afferent feedback and exercise: Some basics}

With the onset of exercise, contraction-induced mechanical and chemical stimuli begin to activate molecular receptors located on the terminal end of both thinly myelinated (group III) and unmyelinated (group IV) nerve fibers with their receptive fields within skeletal muscle. The exercise-induced activation of these receptors increases the spontaneous discharge of the thin fiber muscle afferents (Adreani et al., 1997; Kaufman et al., 1983; Light et al., 2008) (Fig. 1) that project via the dorsal horn of the spinal cord (Wilson and Hand, 1997; Wilson et al., 2002) to various spinal and supraspinal sites within the CNS (Brooks et al., 2005; Craig, 1995; Craig, 2003). Although the role of group III/IV muscle afferents in the circulatory regulation during exercise has been recognized nearly 80 years ago (Alam and Smirk, 1937), for review see (Secher and Amann, 2012), their fundamental importance in determining exercise hyperpnea was not unanimously agreed upon until recently [for review see (Dempsey et al., 2014)], and their 

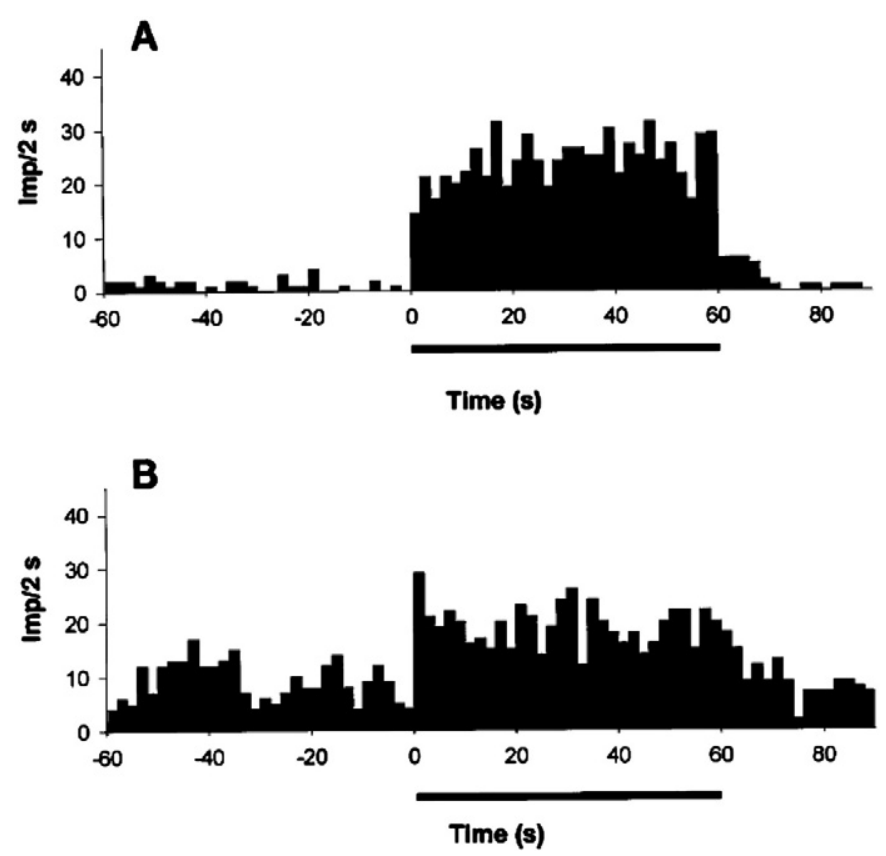

Fig. 1. Discharge frequency [impulses per $2 \mathrm{~s}$; (Imp/2 s)] of group III (panel A) and group IV (panel B) muscle afferents recorded from dorsal root before, during, and after locomotor exercise evoked by electrical stimulation of the mesencephalic locomotor region in decerebrate cats. The horizontal bar denotes the exercise period. Note the immediate increase of both group III and IV locomotor muscle afferent discharge at the onset of exercise and the maintained response until the exercise is terminated. From Adreani et al. (Adreani et al., 1997).

contribution to the development of central fatigue has only been investigated in the last 40 years (Bigland-Ritchie et al., 1986).

With the exception of a few experimental approaches to reduce sensory feedback during and after exercise in humans [e.g. (Gandevia et al., 1990)], the majority of investigations have 'artificially' increased neural discharge of group III/IV muscle afferents to study their role in cardiovascular muscle reflex mechanisms and central fatigue. This approach has included, but was not limited to, intramuscular hypertonic saline (or other metabolite) infusions to stimulate nociceptive muscle afferents (e.g. (Martin et al., 2008) and post exercise circulatory occlusion (PECO) techniques (e.g. (Fisher et al., 2010)) to trap metabolites within a muscle via a blood pressure cuff to maintain/raise neural feedback for as long as the muscle is held ischemic.

\section{Group III/IV muscle afferent feedback effects on the development of peripheral fatigue}

The role of group III/IV muscle afferents on the development of peripheral fatigue is manifested through their contribution to the cardiovascular, hemodynamic, and ventilatory adjustments occurring during exercise. Increases in these parameters arising with the onset of exercise are, next to central command (Waldrop et al., 1996), largely determined by neural feedback from the working muscle and assure augmented blood flow and $\mathrm{O}_{2}$ delivery to the working muscle (Asmussen et al., 1943; Coote et al., 1971; Hollander and Bouman, 1975; Kao, 1963; McCloskey and Mitchell, 1972; Tibes, 1977). Both of these variables depict key components in the rate of development of peripheral fatigue during exercise (Barclay, 1986; Fulco et al., 1996; Katayama et al., 2007). Specifically, decreases in blood flow $/ \mathrm{O}_{2}$ delivery exacerbate this rate, whereas increases in blood flow $/ \mathrm{O}_{2}$ delivery attenuate this rate [for review see (Amann and Calbet, 2008)].

In a recent study designed to investigate the role of group III/IV locomotor muscle afferents in the development of peripheral locomotor muscle fatigue, intrathecal fentanyl was used to attenuate sensory feedback from the lower limb during constant-load leg cycling (Amann et al., 2011a). Peripheral fatigue was quantified via the pre- to postexercise decrease in quadriceps twitch force evoked via supramaximal femoral nerve stimulation. Earlier studies utilizing an identical pharmacological approach to temporarily block group III/IV muscle afferents have documented that exercise in the absence of sensory feedback is characterized by substantial hypoventilation and an attenuated exercise pressor response including decreased central (i.e. cardiac output) and peripheral (leg blood flow) hemodynamic responses during exercise (Amann et al., 2008, 2009, 2010, 2011a, 2011b; Gagnon et al., 2012). Consequently, when constant-load leg cycling is performed in the absence of locomotor muscle afferent feedback, leg blood flow and $\mathrm{O}_{2}$ delivery are markedly attenuated compared to the same exercise performed with an intact neural feedback mechanism. Given the critical role of blood flow $/ \mathrm{O}_{2}$ delivery in the development of fatigue [see above; (Amann and Calbet, 2008)], the rate of accumulation of peripheral fatigue is up to $60 \%$ faster during exercise with impaired vs intact group III/IV muscle afferent feedback (Amann et al., 2011a; Sidhu et al., 2014). Taken together, by facilitating circulatory and ventilatory responses, group III/IV muscle afferent feedback ensures adequate muscle blood flow $/ \mathrm{O}_{2}$ delivery during exercise and thereby prevents premature fatigue at the level of the locomotor muscle. This neural feedback mechanism plays an important role in optimizing fatigue resistance during physical activities in healthy humans.

The arterial baroreflex has been suggested to attenuate the central effects of group III/IV muscle afferents on the exercise pressor response via their interaction in the nucleus tractus solitarii (Kim et al., 2005; Sheriff et al., 1990; Waldrop and Mitchell, 1985). In other words, group III/IV-mediated pressor responses to exercise have been documented to be larger in the absence of the arterial baroreflex. Based on previous experiments in endurance exercising humans showing that attenuated feedback from group III/IV locomotor muscle afferents causes a reduced muscle blood flow $/ \mathrm{O}_{2}$ delivery and accelerated rate of peripheral fatigue (Amann and Secher, 2010, 2011a, 2011b), it could be speculated that arterial baroreflex buffering of group III/IV-mediated muscle reflexes exacerbates the development of peripheral fatigue during exercise. However, Waldrop and Mitchell have shown that the arterial baroreflex modulates the pressor response without changing muscle blood flow during induced muscular contraction in anesthetized cats (Waldrop and Mitchell, 1985). Although unknown in humans, if baroreceptor buffering of muscle afferents does not restrict blood flow to the working muscle, it could be argued that it does not affect the development of peripheral fatigue.

It is important to note that the role of group III/IV muscle afferents in the development of peripheral fatigue might be different in patients with heart failure (Amann et al., 2014) which are characterized by muscle reflex abnormalities (Garry, 2011; Piepoli et al., 2008) with exaggerated afferent feedback as the likely underlying mechanism (Middlekauff and Sinoway, 2007; Notarius et al., 2001; Piepoli and Coats, 2007). Although feedback from these neurons still facilitates central hemodynamics in this population (Amann et al., 2014), it has been documented to account for the excessive hyperventilatory response (Olson et al., 2014) and exaggerated sympathoexcitation (Amann et al., 2014; Notarius et al., 2001) during physical activity in these patients. Recent data demonstrates that when heart failure patients perform single-leg knee-extensor exercise with pharmacologically (lumbar intrathecal fentanyl) blocked group III/IV muscle afferents, sympathetic outflow is attenuated and leg blood flow $/ \mathrm{O}_{2}$ delivery significantly increased compared to control exercise. Importantly, this increase secondary to reduced input from group III/IV muscle afferents causes an attenuated rate of fatigue development in these patients (Amann et al., 2014) (Fig. 2). Therefore, in contrast to healthy individuals in which group III/IV muscle afferent feedback attenuates the rate of peripheral fatigue during exercise (Amann et al., 2011a; Sidhu et al., 2014), the abnormally elevated neural feedback associated with chronic heart failure exacerbates the rate of development of fatigue in these patients (Amann et al., 2014). To our knowledge, there is currently no data 


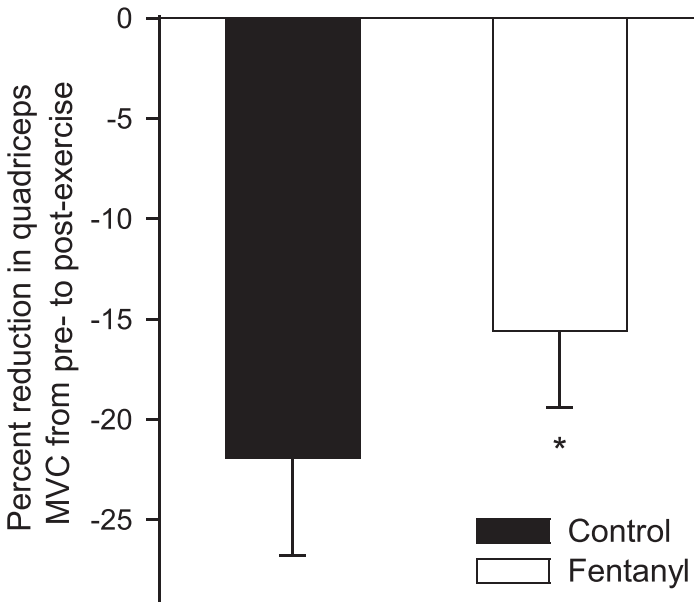

Fig. 2. Reduction in quadricep maximal voluntary contraction strength (MVC) induced via 9 min of constant-load single leg knee-extensor exercise $(25 / 50 / 80 \%$ of peak workload 3 min each) in patients with chronic heart failure. The exercise was performed with intact (control) and blocked (fentanyl) neural feedback from the lower limb. From Amann et al. (Amann et al., 2014).

available on the effects of other diseases characterized by abnormal neural feedback from group III/IV muscle afferents (e.g., hypertension) on the development of central and peripheral fatigue during exercise.

\section{Group III/IV muscle afferent feedback effects on the development of central fatigue}

The involvement of group III/IV muscle afferents in the development of central fatigue during exercise is mediated through their inhibitory effect on the output from spinal motoneurons (i.e. neural 'drive' to motor units) which causes a reduction in muscle activation and consequently exercise performance (Amann et al., 2008, 2009, 2013; Bigland-Ritchie et al., 1986; Gandevia et al., 1996; Sidhu et al., 2014; Taylor et al., 1996). This was initially shown during maximal isometric exercise of a single muscle/muscle group [for a review see (Gandevia, 2001)]. For example, when the discharge rate, and thus the central projection, of group III/IV muscle afferents is maintained following a 2 min maximal voluntary elbow flexor contraction (via PECO), spinal motoneuronal output and voluntary muscle activation remain low and do not recover until circulation is restored and the firing frequency of group III/IV muscle afferents recovers (Gandevia et al., 1996; Taylor et al., 2000).

The inhibitory effect of group III/IV muscle afferents on the output from spinal motoneurons and the associated decrease in exercise performance (secondary to reduced muscle activation) are also of critical relevance during whole-body exercise. Specifically, when subjects perform high-intensity cycling exercise with pharmacologically blocked group III/IV locomotor muscle afferents, the inhibitory effect of these sensory neurons is 'attenuated' and the output from spinal motoneurons less restricted and significantly higher compared to that observed during the identical exercise performed with intact feedback (Amann et al., 2008, 2009, 2011a). More recent cycling studies used lumbar intrathecal fentanyl to block group III/IV locomotor muscle afferents during strenuous cycling exercise to investigate their role on maximal voluntary muscle activation (key indicator of central fatigue) after exercise. While maximal voluntary quadricep activation was substantially decreased immediately after exhaustive bike exercise with intact feedback, this impact was abolished when the same exercise was repeated with blocked locomotor muscle afferents. Furthermore, it is interesting that group III/IV-mediated locomotor muscle feedback associated with exhaustive leg cycling also compromise maximal voluntary muscle activation (during and after exercise) of a remote muscle group (i.e. elbow flexors) not directly involved in the task (Sidhu et al., 2014). These recent findings directly emphasize the significant involvement of group III/IV muscle afferents in the development of central fatigue during intense whole body endurance exercise.

Investigating the effect of group III/IV muscle afferents on whole body exercise performance is challenging. The difficulty has been arising from the twofold role these neurons play in an exercising human. Specifically, although they limit spinal motoneuronal output and facilitate central fatigue (i.e. limiting effect on performance), their contribution to the prevention of premature peripheral fatigue by facilitating circulatory and ventilatory responses during exercise is essential (i.e. facilitating effect on performance; see above). Therefore, manipulating muscle afferents during exercise affects both sides and the net effect depends on how one effect outweighs the other. In a recent study designed to circumvent this caveat, subjects were asked to perform dynamic single leg knee-extensor exercise to exhaustion in one leg immediately followed by the identical task in the other leg (Amann et al., 2013). The goal was to determine whether afferent feedback arising from the kneeextensor exercised/exhausted first inhibits spinal motoneuronal output and thereby limits endurance exercise performance of the consecutively exercising contralateral knee-extensor. The design of the study and additional control experiments allowed the exclusion of other limiting and confounding influences on the endurance performance of the consecutively exercising contralateral knee-extensor (e.g. lack of peripheral fatigue, uncompromised ventilatory and/or hemodynamic responses, etc.). Afferent feedback associated with exercise to exhaustion in the first leg ( $\sim 9 \mathrm{~min}$ ) reduced endurance time to exhaustion of the consecutively exercised contralateral leg by $\sim 49 \%$ (from $\sim 9 \mathrm{~min}$ to $\sim 5 \mathrm{~min}$ ). It was concluded that group III/IV muscle afferent feedback associated with exhaustive endurance exercise has an inhibitory effect on the CNS which limits the output of spinal motoneurons and therefore endurance performance (Amann et al., 2013).

\subsection{How do group III/IV muscle afferents limit the output from spinal motoneurons?}

Decreases in the output from spinal motoneurons have been suggested to result from group III/IV muscle afferent feedback inhibiting voluntary descending drive 'upstream' of the motor cortex and/or an afferent-mediated depression of the net responsiveness of the corticospinal tract including motor cortical cells and spinal motoneurons (Hilty et al., 2011; Martin et al., 2006; Sidhu et al., 2014; Taylor et al., 2000, 2006). Although the inhibition of voluntary descending drive through muscle afferents acting upstream of the motor cortex is generally accepted as the key mechanism of group III/IV-related central fatigue, the significance of the corticospinal tract responsiveness (and its susceptibility to neural feedback) in the context of central fatigue remains ambiguous. Four types of inconsistent observations fuel this controversy.

First, studies based on maximal isometric single muscle contraction and PECO suggest a dissociation between group III/IV muscle afferent feedback and alterations in the responsiveness of the corticospinal tract (Gandevia et al., 1996; Taylor et al., 2000). Specifically, the responsiveness of both spinal motoneurons and motor cortical output cells was shown to recover despite continuous afferent firing following exercise (via PECO) (Taylor et al., 2000). Second, in direct contrast to this, other single-joint studies suggest that stimulation of group III/IV muscle afferents via PECO or hypertonic saline causes a net corticospinal depression resulting from a motor cortical inhibition combined with either facilitated (Martin et al., 2008) or inhibited (Martin et al., 2006) spinal motoneurons. Third, exercise-induced decreases in voluntary muscle activation during maximal, isometric single-joint contractions may be unrelated to alterations in corticospinal responsiveness. This was concluded based on the observation that despite continuous afferent firing following fatiguing elbow flexion (via PECO), the responsiveness of both the spine and the brain recovered while voluntary muscle activation 
remained depressed and only recovered after the cuff was released and afferent firing decreased (Gandevia et al., 1996; Taylor et al., 2000). Fourth, studies using pharmacological blockade of group III/IV muscle afferents during exhaustive whole body endurance exercise (i.e. cycling) suggest that exercise-induced decreases in the responsiveness of motor cortical output cells coincide with a restricted output from spinal motoneurons and a decrease in voluntary muscle activation (Sidhu et al., 2014). Taken together, the actual role of exerciseinduced alterations on corticospinal tract responsiveness in central fatigue, and the influence of group III/IV afferents on these changes, remain elusive. Some of the controversial observations briefly mentioned in this section might be explained by potential differences between exercise modalities (Sidhu et al., 2013) and/or a combination of issues discussed below.

\section{Subtypes of group III/IV muscle afferents: critical considerations on anatomical and functional differences}

Recently, two different subtypes of chemosensitive group III/IV muscle afferents characterized by anatomical and functional differences have been discovered in animals (Birdsong et al., 2010; Gautam and Benson, 2013; Jankowski et al., 2013; Light et al., 2008; Naves and McCleskey, 2005) and humans (Pollak et al., 2014). One subtype, the so-called metabo- or ergoreceptors, was documented to only respond to innocuous levels of intramuscular metabolites (lactate, ATP, protons) associated with 'normal' (i.e. freely perfused and predominantly aerobic) exercise (Bangsbo et al., 1993; Hellsten et al., 1998; Li et al., 2003) up to strenuous intensities. In contrast, the other subtype, the socalled metabo-nociceptors, only respond to higher (and concurrently noxious) levels of metabolites present in muscle during ischemic contractions or following hypertonic saline infusions-but not to nonnoxious metabolite concentrations associated with normal exercise (Jankowski et al., 2013; Light et al., 2008; Pollak et al., 2014).

The specific phenotypical distinction of metaboreceptors vs metabonociceptors remains elusive to date. It is, however, recognized that molecular differences between the subtypes includes the differential expression of purinergic receptors ( $\mathrm{P} 2 \mathrm{X} 2,3,4)$, transient receptor potential vanilloid type 1 and/or 2 (TRPV1/2), and acid-sensing ion channels 1, 2, and 3 (ASIC 1-3) (Birdsong et al., 2010; Gautam and Benson, 2013; Jankowski et al., 2013; Light et al., 2008). Although the two different subtypes of group III/IV muscle afferents project to the same location in the superficial dorsal horn (Jankowski et al., 2013), it is currently unknown to what degree each subtype is anatomically linked to lamina I neurons which have direct projections to various supraspinal sites.

The recent recognition of functional and structural differences between metaboreceptors and metabo-nociceptors (Birdsong et al., 2010; Gautam and Benson, 2013; Jankowski et al., 2013; Light et al., 2008; Naves and McCleskey, 2005; Pollak et al., 2014) suggests that PECO or hypertonic saline infusions may no longer be considered optimal techniques for investigating the role of those group III/IV muscle afferents which are active during normal, freely perfused exercise of light to strenuous intensity (i.e. ergoreceptors) on circulation, ventilation and central fatigue. This is simply because these techniques likely evoke neural feedback which is mediated via the metabo-nociceptors which may not even be active during normal exercise/activity. Furthermore, investigations addressing the effects of cardiovascular pathologies (e.g. heart failure) in humans and animals on the sensitivity of group III vs group IV muscle afferents using PECO or other noxious stimuli might focus more on metabo-nociceptive pathways and thereby contribute to the controversy surrounding this question (Middlekauff and Sinoway, 2007; Piepoli and Coats, 2007). Taken together, recent critical discoveries addressing the existence of different subtypes of group III/IV muscle afferents (Birdsong et al., 2010; Gautam and Benson, 2013; Jankowski et al., 2013; Light et al., 2008; Naves and McCleskey, 2005; Pollak et al., 2014) caution a careful consideration of hypertonic saline and PECO studies (i.e. musculoskeletal pain) intended to address the role of group III/IV-mediated neural feedback during exercise.

\section{Conclusion}

Group III and IV muscle afferents play a significant role in the development of fatigue during exercise in humans. These sensory neurons determine autonomic responses to exercise which assure adequate muscle blood flow $/ \mathrm{O}_{2}$ delivery during physical activity and are a key determinant in minimizing the rate of peripheral fatigue development and optimizing exercise performance. However, the very same muscle afferents also exert inhibitory effects on the CNS which diminishes the output from spinal motoneurons, decreases voluntary muscle activation (i.e. facilitates central fatigue), and impairs exercise performance. Despite the fact that group III/IV muscle afferents might be considered a "double-edged sword" (Amann and Secher, 2010), feedback from these sensory neurons assures adequate ventilatory and circulatory responses and protects the exercising human from potentially catastrophic exercise-induced homeostatic failure by a CNS-mediated restriction of muscular activities.

\section{References}

Adreani, C.M., Hill, J.M., Kaufman, M.P., 1997. Responses of group III and IV muscle afferents to dynamic exercise. J. Appl. Physiol. 82, 1811-1817.

Alam, M., Smirk, F.H., 1937. Observations in man upon a blood pressure raising reflex arising from the voluntary muscles. J. Physiol. 89, 372-383.

Allen, D.G., Lamb, G.D., Westerblad, H., 2008. Skeletal muscle fatigue: cellular mechanisms. Physiol. Rev. 88, 287-332.

Amann, M., Calbet, J.A., 2008. Convective oxygen transport and fatigue. J. Appl. Physiol $104,861-870$

Amann, M., Secher, N.H., 2010. Afferent feedback from fatigued locomotor muscles is an important determinant of endurance exercise performance. J. Appl. Physiol. 108, 452-454.

Amann, M., Proctor, L.T., Sebranek, J.J., Eldridge, M.W., Pegelow, D.F., Dempsey, J.A., 2008 Somatosensory feedback from the limbs exerts inhibitory influences on central neural drive during whole body endurance exercise. J. Appl. Physiol. 105, 1714-1724.

Amann, M., Proctor, L.T., Sebranek, J.J., Pegelow, D.F., Dempsey, J.A., 2009. Opioidmediated muscle afferents inhibit central motor drive and limit peripheral muscle fatigue development in humans. J. Physiol. 587, 271-283.

Amann, M., Blain, G.M., Proctor, L.T., Sebranek, J.J., Pegelow, D.F., Dempsey, J.A., 2010 Group III and IV muscle afferents contribute to ventilatory and cardiovascular response to rhythmic exercise in humans. J. Appl. Physiol. 109, 966-976.

Amann, M., Blain, G.M., Proctor, L.T., Sebranek, J.J., Pegelow, D.F., Dempsey, J.A., 2011a. Implications of group III and IV muscle afferents for high intensity endurance exercise performance in humans. J. Physiol. 589, 5299-5309.

Amann, M., Runnels, S., Morgan, D.E., Trinity, J.D., Fjeldstad, A.S., Wray, D.W., Reese, V.R Richardson, R.S., 2011b. On the contribution of group III and IV muscle afferents to the circulatory response to rhythmic exercise in humans. J. Physiol. 589, 3855-3866.

Amann, M., Venturelli, M., Ives, S.J., McDaniel, J., Layec, G., Rossman, M.J., Richardson, R.S. 2013. Peripheral fatigue limits endurance exercise via a sensory feedback-mediated reduction in spinal motoneuronal output. J. Appl. Physiol. 115, 355-364.

Amann, M., Venturelli, M., Ives, S.J., Morgan, D.E., Gmelch, B., Witman, M.A., Jonathan Groot, H., Wray, W.D., Stehlik, J., Richardson, R.S., 2014. Group III/IV muscle afferents impair limb blood in patients with chronic heart failure. Int. J. Cardiol. 174, 368-375.

Asmussen, E., Nielsen, M., Wieth-Pedersen, G., 1943. Cortical or reflex control of respiration during muscular work. Acta Physiol. Scand. 6, 168-175.

Bangsbo, J., Johansen, L., Graham, T., Saltin, B., 1993. Lactate and H+ effluxes from human skeletal muscles during intense, dynamic exercise. J. Physiol. 462, 115-133.

Barclay, J.K., 1986. A delivery-independent blood flow effect on skeletal muscle fatigue. J. Appl. Physiol. 61, 1084-1090.

Bigland-Ritchie, B.R., Dawson, N.J., Johansson, R.S., Lippold, O.C., 1986. Reflex origin for the slowing of motoneurone firing rates in fatigue of human voluntary contractions. J. Physiol. 379, 451-459.

Birdsong, W.T., Fierro, L., Williams, F.G., Spelta, V., Naves, L.A., Knowles, M., MarshHaffner, J., Adelman, J.P., Almers, W., Elde, R.P., McCleskey, E.W., 2010. Sensing muscle ischemia: coincident detection of acid and ATP via interplay of two ion channels. Neuron 68, 739-749.

Brooks, J.C., Zambreanu, L., Godinez, A., Craig, A.D., Tracey, I., 2005. Somatotopic organisation of the human insula to painful heat studied with high resolution functional imaging. Neuroimage 27, 201-209.

Coote, J.H., Hilton, S.M., Perez-Gonzalez, J.F., 1971. The reflex nature of the pressor response to muscular exercise. J. Physiol. 215, 789-804.

Craig, A.D., 1995. Distribution of brainstem projections from spinal lamina I neurons in the cat and the monkey. J. Comp. Neurol. 361, 225-248.

Craig, A.D., 2003. Pain mechanisms: labeled lines versus convergence in central processing Annu. Rev. Neurosci. 26, 1-30.

Dempsey, J.A., Blain, G.M., Amann, M., 2014. Are type III-IV muscle afferents required for a normal steady state exercise hyperpnea in humans? J. Physiol. 592, 463-474. 
Fisher, J.P., Seifert, T., Hartwich, D., Young, C.N., Secher, N.H., Fadel, P.J., 2010. Autonomic control of heart rate by metabolically sensitive skeletal muscle afferents in humans. J. Physiol. 588, 1117-1127.

Fulco, C.S., Lewis, S.F., Frykman, P.N., Boushel, R., Smith, S., Harman, E.A., Cymerman, A Pandolf, K.B., 1996. Muscle fatigue and exhaustion during dynamic leg exercise in normoxia and hypobaric hypoxia. J. Appl. Physiol. 81, 1891-1900.

Gagnon, P., Bussieres, J.S., Ribeiro, F., Gagnon, S.L., Saey, D., Gagne, N., Provencher, S., Maltais, F., 2012. Influences of spinal anesthesia on exercise tolerance in patients with chronic obstructive pulmonary disease. Am. J. Respir. Crit. Care Med. 186, 606-615.

Gandevia, S.C., 2001. Spinal and supraspinal factors in human muscle fatigue. Physiol. Rev. $81,1725-1789$

Gandevia, S.C., Macefield, G., Burke, D., McKenzie, D.K., 1990. Voluntary activation of human motor axons in the absence of muscle afferent feedback. The control of the deafferented hand. Brain 113 (Pt 5), 1563-1581.

Gandevia, S.C., Allen, G.M., Butler, J.E., Taylor, J.L., 1996. Supraspinal factors in human muscle fatigue: evidence for suboptimal output from the motor cortex. J. Physiol. 490 (Pt 2), 529-536.

Garry, M.G., 2011. Abnormalities of the exercise pressor reflex in heart failure. Exerc. Sport Sci. Rev. 39, 167-176.

Gautam, M., Benson, C.J., 2013. Acid-sensing ion channels (ASICs) in mouse skeletal muscle afferents are heteromers composed of ASIC1a, ASIC2, and ASIC3 subunits. FASEB J. 27, 793-802.

Hellsten, Y., Maclean, D., Radegran, G., Saltin, B., Bangsbo, J., 1998. Adenosine concentrations in the interstitium of resting and contracting human skeletal muscle. Circulation $98,6-8$.

Hilty, L., Lutz, K., Maurer, K., Rodenkirch, T., Spengler, C.M., Boutellier, U., Jancke, L., Amann, M., 2011. Spinal opioid receptor-sensitive muscle afferents contribute to the fatigueinduced increase in intracortical inhibition in healthy humans. Exp. Physiol. 96, 505-517.

Hollander, A.P., Bouman, L.N., 1975. Cardiac acceleration in man elicited by a muscle-heart reflex. J. Appl. Physiol. 38, 272-278.

Jankowski, M.P., Rau, K.K., Ekmann, K.M., Anderson, C.E., Koerber, H.R., 2013. Comprehensive phenotyping of group III and IV muscle afferents in mouse. J. Neurophysiol. 109, 2374-2381.

Kao, F.F., 1963. An experimental study of the pathway involved in exercise hyperpnea employing cross-circulation technique. In: Cunningham, D.J.C., Lloyd, B.B. (Eds.), The Regulation of Human Respiration. Blackwell, Oxford, pp. 461-502.

Katayama, K., Amann, M., Pegelow, D.F., Jacques, A.J., Dempsey, J.A., 2007. Effect of arteria oxygenation on quadriceps fatigability during isolated muscle exercise. Am. J. Physiol. Regul. Integr. Comp. Physiol. 292, R1279-R1286.

Kaufman, M.P., Longhurst, J.C., Rybicki, K.J., Wallach, J.H., Mitchell, J.H., 1983. Effects of static muscular contraction on impulse activity of groups III and IV afferents in cats. J. Appl. Physiol. 55, 105-112.

Kim, J.K., Sala-Mercado, J.A., Rodriguez, J., Scislo, T.J., O'Leary, D.S., 2005. Arterial baroreflex alters strength and mechanisms of muscle metaboreflex during dynamic exercise. Am. J. Physiol. Heart Circ. Physiol. 288, H1374-H1380.

Li, J., King, N.C., Sinoway, L.I., 2003. ATP concentrations and muscle tension increase linearly with muscle contraction. J. Appl. Physiol. 95, 577-583.

Light, A.R., Hughen, R.W., Zhang, J., Rainier, J., Liu, Z., Lee, J., 2008. Dorsal root ganglion neurons innervating skeletal muscle respond to physiological combinations of protons, ATP, and lactate mediated by ASIC, P2X, and TRPV1. J. Neurophysiol. 100, 1184-1201.

Martin, P.G., Smith, J.L., Butler, J.E., Gandevia, S.C., Taylor, J.L., 2006. Fatigue-sensitive afferents inhibit extensor but not flexor motoneurons in humans. J. Neurosci. 26 4796-4802.

Martin, P.G., Weerakkody, N., Gandevia, S.C., Taylor, J.L., 2008. Group III and IV muscle afferents differentially affect the motor cortex and motoneurones in humans. J. Physiol $586,1277-1289$
McCloskey, D.I., Mitchell, J.H., 1972. Reflex cardiovascular and respiratory responses originating in exercising muscle. J. Physiol. 224, 173-186.

Middlekauff, H.R., Sinoway, L.I., 2007. Increased mechanoreceptor stimulation explains the exaggerated exercise pressor reflex seen in heart failure. J. Appl. Physiol. 102, 492-494 (Discussion 496).

Naves, L.A., McCleskey, E.W., 2005. An acid-sensing ion channel that detects ischemic pain. Braz. J. Med. Biol. Res. 38, 1561-1569.

Notarius, C.F., Atchison, D.J., Floras, J.S., 2001. Impact of heart failure and exercise capacity on sympathetic response to handgrip exercise. Am. J. Physiol. Heart Circ. Physiol. 280, H969-H976.

Olson, T.P., Joyner, M.J., Eisenach, J.H., Curry, T.B., Johnson, B.D., 2014. Influence of locomotor muscle afferent inhibition on the ventilatory response to exercise in heart failure. Exp. Physiol. 99, 414-426.

Piepoli, M.F., Coats, A.J., 2007. Increased metaboreceptor stimulation explains the exaggerated exercise pressor reflex seen in heart failure. J. Appl. Physiol. 102, 494-496 (discussion 496-497)

Piepoli, M.F., Dimopoulos, K., Concu, A., Crisafulli, A., 2008. Cardiovascular and ventilatory control during exercise in chronic heart failure: role of muscle reflexes. Int. J. Cardiol. 130, 3-10.

Pollak, K.A., Swenson, J.D., Vanhaitsma, T.A., Hughen, R.W., Jo, D., Light, K.C., Schweinhardt, P., Amann, M., Light, A.R., 2014. Exogenously applied muscle metabolites synergistically evoke sensations of muscle fatigue and pain in human subjects. Exp. Physiol. 99 (2), 368-380.

Secher, N.H., Amann, M., 2012. Human investigations into the exercise pressor reflex. Exp. Physiol. 97, 59-69.

Sheriff, D.D., O'Leary, D.S., Scher, A.M., Rowell, L.B., 1990. Baroreflex attenuates pressor response to graded muscle ischemia in exercising dogs. Am. J. Physiol. 258, H305-H310.

Sidhu, S.K., Cresswell, A.G., Carroll, T.J., 2013. Corticospinal responses to sustained locomotor exercises: moving beyond single-joint studies of central fatigue. Sports Med. 43, 437-449.

Sidhu, S.K., Weavil, J.C., Venturelli, M., Garten, R.S., Rossman, M.J., Richardson, R.S., Gmelch, B.S., Morgan, D.E., Amann, M., 2014. Spinal $\mu$-opioid receptor sensitive lower limb muscle afferents determine corticospinal responsiveness and exacerbate central fatigue in upper limb muscle. J. Physiol. http://dx.doi.org/10.1113/jphysiol. 2014.2754382014.

Taylor, J.L., Butler, J.E., Allen, G.M., Gandevia, S.C., 1996. Changes in motor cortical excitability during human muscle fatigue. J. Physiol. 490 (Pt 2), 519-528.

Taylor, J.L., Petersen, N., Butler, J.E., Gandevia, S.C., 2000. Ischaemia after exercise does not reduce responses of human motoneurones to cortical or corticospinal tract stimulation. J. Physiol. 525 (Pt 3), 793-801.

Taylor, J.L., Todd, G., Gandevia, S.C., 2006. Evidence for a supraspinal contribution to human muscle fatigue. Clin. Exp. Pharmacol. Physiol. 33, 400-405.

Tibes, U., 1977. Reflex inputs to the cardiovascular and respiratory centers from dynamically working canine muscles. Some evidence for involvement of group III or IV nerve fibers. Circ. Res. 41, 332-341.

Waldrop, T.G., Mitchell, J.H., 1985. Effects of barodenervation on cardiovascular responses to static muscular contraction. Am. J. Physiol. 249, H710-H714.

Waldrop, T.G., Eldridge, F.L., Iwamoto, G.A., Mitchell, J.H., 1996. Central neural control of respiration and circulation during exercise. In: Rowell, L.B., Shepherd, J.T. (Eds.), Handbook of Physiology Section 12: Exercise: Regulation and Integration of Multiple Systems. Oxford University Press, New York, pp. 333-380.

Wilson, L.B., Hand, G.A., 1997. The pressor reflex evoked by static contraction: neurochemistry at the site of the first synapse. Brain Res. Brain Res. Rev. 23, 196-209.

Wilson, L.B., Andrew, D., Craig, A.D., 2002. Activation of spinobulbar lamina I neurons by static muscle contraction. J. Neurophysiol. 87, 1641-1645. 